\title{
The impacts of the trade liberalization of environmental goods on power system and
}

\section{$\mathrm{CO}_{2}$ emissions}

Xiurong $\mathrm{Hu}^{1}$, Hector Pollitt ${ }^{2,3}$, Jamie Pirie ${ }^{2}$, Jean-Francois Mercure ${ }^{4,3,2}$, Junfeng Liu ${ }^{1}$, Jing Meng $^{5}$, Shu Tao ${ }^{1}$

${ }^{1}$ Laboratory for Earth Surface Processes, College of Urban and Environmental Sciences, Peking University, Beijing 100871, China.

${ }^{2}$ Cambridge Econometrics Ltd, Covent Garden, Cambridge CB1 2HT, United Kingdom

${ }^{3}$ Cambridge Centre for Environment, Energy and Natural Resource Governance (CEENRG), University of Cambridge, Cambridge, United Kingdom

${ }^{4}$ Department of Geography, University of Exeter, Rennes Drive, Exeter EX4 4RJ, United Kingdom

${ }^{5}$ The Bartlett School of Construction and Project Management, University College London, London WC1E 7HB, United Kingdom

*Correspondence to: Junfeng Liu (E-mail: jfliu@ @ku.edu.cn)

\begin{abstract}
The trade liberalization of Environmental Goods (EG), through as Environmental Goods Agreement (EGA), is crucial in low carbon electricity technology diffusion. However, there is a big gap of the EG definition lists and the integrated effectiveness analysis of EGA. This paper analyses the effects of the trade liberalization of EG based on macroeconomic and electricity sector models and attempts to find a more efficient EG trade policy by comparing different EG lists, considering end-use control and combining the EG policy with a carbon
\end{abstract}


tax. The results show that the trade liberalization of EG does not necessarily benefit the environment without other policies, as the effects of the multiple end-uses of EG on conventional energy might result in environmental damage. We find that merging an EGA into a global carbon tax system would enhance the effects of carbon tax on $\mathrm{CO}_{2}$ reduction by $33 \%$, and simultaneously lower the GDP loss due to the carbon tax by $75 \%$. The economic benefits from the EGA could offset the costs of other environmental policies. Thus, end-use control and other environmental policies should be considered at both the global and regional levels in the setting of international trade agreements that target EG.

Keywords: Environmental Goods Agreement, trade liberalization of environmental goods, E3ME model, energy technology, carbon tax

\section{Introduction}

There is a strong consensus that global average surface temperature rise must be kept below $2{ }^{\circ} \mathrm{C}$ to avoid dangerous environmental changes (Randalls 2010). Previous studies have shown that achieving these targets requires a full-scale decarbonisation of the electricity system (Williams et al 2012; Krey et al 2014). The decarbonisation of the global power system depends first and foremost on transforming the power sector from carbon-intensive and inefficient to renewable and highly efficient systems (Mitchell 2016). Global renewable electricity transformation relies on renewable energy technologies diffusion, which is partially influenced by the international trade policy of environmental goods. Environmental goods (EG), which are produced to measure, prevent, control, clean up or recover environment damage, are vital for a green economy (De Alwis 2014). Trade plays an important role in accelerating the diffusion and uptake of EG (Bucher et al 2014). There have been more negotiations of trade barriers on environmental goods (EG) in recent years (Wan 
et al 2018). These negotiations intend to reduce pollution and emission damages by increasing the ability to obtain high quality EG and reducing the technology cost of environmental protection, which is crucial in the sustainable economic development process as it sustains potential benefits for promoting environmental protection and economic development.

The Environmental Goods Agreement (EGA) on the reduction and elimination of trade barriers for EG has been negotiated since the late 1990s (Steenblik 2005; Nimubona 2010). The negotiations on EG in the Doha Development Agenda of the World Trade Organization (WTO) in 2001 were expected to be an important stage to reduce the trade barriers for EG. Afterwards, the Asia-Pacific Economic Cooperation (APEC) and Organisation for Economic Co-operation and Development (OECD) listed their own EG products (Steenblik 2005). Then, a group of countries proposed a "Friends of Environmental Goods" that included 153 products in 2007 (LaFleur 2011). In 2011, the WTO identified 408 products on an EG list, of which a core list of $26 \mathrm{EG}$ is a starting point for negotiation (De Alwis 2014). Additionally, the APEC group concluded to reduce tariffs on a list of 54 environmental product categories to 5\% or less by 2015 (Arun and Anders 2016). Since 2014, the EU and 16 other countries in the WTO have been engaging in an EGA to remove the barriers to trade for environmental goods (WTO ; European Commission 2016). Until now, several lists of EG were proposed that ranged from 26 to 536 products for different groups with different purposes. The EG definition (or classification) is the area most actively debated in the negotiations. The main reasons for this focus are the following: (1) The Harmonized System (HS) code used to draft an EG list was set for trade and customs but was not designed for end-use, thus some environmental goods have no equivalent HS commodity code and some HS commodity codes may include non-environmental goods (Steenblik 2005); (2) The products have multiple enduse problems such that they might be used for both environmental and non-environmental 
purposes. For example, pumps can be used in clean technology facilities or in industrial uses not related to environmental remediation (Razzaque and Chaytor 2004); (3) The entire lifecycle emissions or pollution should be accounted for to decide whether it is a truly environmentally friendly product. For instance, wind turbines depend on rare metals whose production process could generate toxic acids and cause serious air pollution problems (Melo and Vijil 2014).

Therefore, comparing the existing EG lists is important to making a further internationally agreed EG list. Steenblik (2005) compared the different purposes and tariffs between the APEC list and the WTO list. European Commission (2016) compared the trade value and tariffs of the cumulative lists of the APEC list + Friends list, the Chairs list (with 536 products including APEC) and all goods included in these three lists. Hammeren (2014) analysed sustainable development under the APEC and WTO lists. Few studies have qualified the environmental effects of different EG lists. Zugravu-Soilita (2018) compared the OECD, APEC and United Nations Conference on Trade and Development (UNCTAD) lists. He suggested that the more comprehensive UNCTAD lists, which include both the traditional EG and environmentally preferable products, are better for the economy and environment. However, he estimated only the effects of EG trade on central and eastern Europe from 1995 to 2003. In this paper, we simulate the global effects of EG trade liberalization through the electricity sector according to the narrowest list (Core lists) and broadest list (WTO list) of the WTO for 2030. Moreover, as one of the main reasons for EG list uncertainty, we also consider the effects of multiple end-uses of EG.

Trade liberalization of EG, means reducing all tariffs of EG and aims to improve the technology of clean energy that originates from lower costs. EG generally include equipment and facilities such as scrubbers, catalytic converters, wind turbines, solar panels and air treatment filters. The trade liberalization of EG could decrease import prices and encourage 
the production of clean energy facilities with lower costs. Dijkstra and Mathew (2016) pointed out that trade liberalization usually results in cleaner production and contributes to higher welfare. Wan et al (2018) used a two countries model to find that trade liberalization in EG could improve the welfare for the country who has smaller demand for EG, experiences less damage from the production of dirty input, or values more environment improvement. De Alwis (2014) found that the elimination of tariffs on EG trade could reduce $\mathrm{SO}_{2}$ emissions, and the falling pollution due to EG trade liberalization has no relationship with the income level of the country. Zugravu-Soilita (2018) noted that higher trade intensity in $\mathrm{EG}$ could reduce $\mathrm{CO}_{2}$ emissions, but have no significant effect on $\mathrm{SO}_{2}$ emissions. These studies analysed only the impact of trade liberalization of EG on emissions based on time series data. There is no detailed analysis of the EG liberalization impact on energy structures. The current study attempts to investigate the impacts of the reduction on the tariffs of EG through the energy mix changes in the electricity sector.

Moreover, the EGA could also impact regional environmental regulations. The decrease in technology costs from reducing tariffs could stimulate local government to set more ambitious environmental targets (Nimubona 2010). However, the EGA might also negatively impact the environment. Sometimes, there is a risk of a rebound effect as the lower costs of clean production leads to an increase in overall production, which would offset the first order reductions in pollution from cleaner production methods (Zugravu-Soilita 2018). Furthermore, the dirty intermediate goods for special EG production could increase pollution (Wan et al 2018). However, these studies were based only on historical data or they built the model according to special countries. Different from the above studies, this paper sets the environmental policy as an exogenous variable and simulates the effects of the EGA, environmental policy and the combination of them for 59 regions for 2030. 
Consequently, this study aims to fill the gap in the existing literature on EG with an analysis of the EGA by using an integrated economic-energy-environmental approach based on the Energy-Environmental-Economy Macroeconomic (E3ME) and Future Technology Transformation (FTT) models. It then attempts to find a more efficient EG trade policy through comparing different EG lists by considering end-use control and combining them with other environmental policies. This study focuses on the subset of EG related to power generation technology, as the power sector is the most important part of the energy structure and the largest $\mathrm{CO}_{2}$ emissions source.

The paper is structured as follows. Following this introduction, section 2 specifies the model, database and scenario setting. Section 3 presents the model results and discussions. Section 4 presents the conclusions, implications and limitations of this study.

\section{Methodology}

E3ME, an integrated macroeconomic model for global economic, energy and environmental analysis, is used to assess the impact of the EGA through the changes in the power sector's energy mix. The E3ME model incorporates the detailed bottom-up power sector model, FTT, which covers 24 different energy technologies. We first calculate the trade liberalization of EG impact on power generation technology costs, then put it into the E3ME-FTT combined model to simulate the changes in the power mix. These changes then provide feedback to the rest of the model to calculate the changes in energy demand and emissions, and the wider macroeconomic impacts.

2.1 Changes in power generation technology costs 
The changes in power generation technology costs are calculated through the changes in prices of EG and the contribution of EG to each generation technology. Reductions in tariffs will decrease the import prices of EG. Since the data do not allow us to distinguish the EG produced domestically or imported from other countries for each region, we assume that domestic producers will reduce prices consistently with import prices, and that the installation costs are unchanged based on European Commission (2015). Thus, once we know the EG share of the total cost of production for a particular technology, we can obtain the reduction in generation technology cost.

$$
T C_{e}=\Delta P D_{e} * R C_{e}
$$

The $\triangle P D_{e}$ is the change of domestic EG price caused by the reductions of the tariffs of EG. The $R C_{e}$ is the EG share of the total cost of production for a particular technology and the data are from the International Renewable Energy Agency. The detailed EG used for power generation technology and their average tariffs are listed in Table A1 of the Supplementary Information, including the goods for renewable energy technologies, conventional technologies and broader economic sectors. The contributions of EG to power generation technology are shown in Table A2 of the Supplementary Information. The change in technology cost is entered into the E3ME-FTT model exogenously.

\subsection{The E3ME and FTT models}

E3ME is an integrated assessment model in which dynamic (time-dependent) human or natural behaviour is driven by empirically-determined dynamic relationships. A chosen set of econometric relationships (equations) is regressed on the historical data and is projected into the future. There are 33 sets of econometrically estimated equations, including the components of GDP, prices, energy demand and material demand, and 59 global regions, with 43 sectors in each region in the model. Each equation set is disaggregated by country 
and by sector and the regions are linked through bilateral trade equations. The historical database of the model covers the period 1970-2016, and the model projects forward annually to 2050 (Cambridge Econometrics 2014).

The structure of E3ME is based on the national accounting system, with further linkages to energy demand and environmental emissions. Thus, there are three modules: economy, energy and environment. Each module has its own units of account and sources of data. The economy module provides the economic activity and price levels to the energy module; the energy module then feeds back with the demands and prices changes of energy consumption, which will determine emissions levels and also affect the economy. Thus, the E3ME model can be widely used in carbon price and environmental tax analysis (Barker et al 2007; Pollitt et al 2015; Lee et al 2017). The model manual is available at the model website

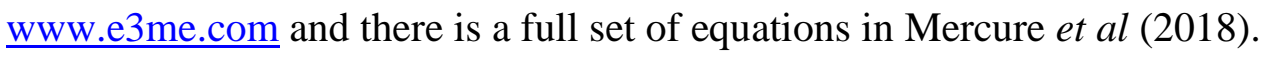

A "bottom-up" electricity model is combined with E3ME called Future Technology Transformations (FTT) and is used to analyse energy and climate change policy through the electricity sector (Mercure et al 2014; Pollitt et al 2014; Mercure et al 2018). The FTT model represents global power systems based on market price competition, induced natural resource use and technological substitution. The FTT: power model is the first power sector model based on a dynamic set of coupled logistic differential equations, of the Lotka-Volterra family, which shows a gradual technological substitution process (Mercure 2012). FTT calculates a power generation mix from 24 technologies, and the model estimated future shares for each one based on prices and other technology characteristics. Unlike most energy system models that operate on optimization, this model simulates real-world behaviour in terms of investment choices. It is therefore well suited for the EGA and carbon tax analysis in an imperfectly competitive market. 
E3ME model is often compared to another type of widespread macroeconomic model, the Computable General Equilibrium (CGE) model (Mercure et al 2019). The scenario sets and inputs are similar to both models. However, there are key differences between E3ME model and a CGE model. Opposing to the neoclassical theory for Computable General Equilibrium models, E3ME avoids assumptions about optimisation and perfect markets which have been questioned in real world. Fundamental uncertainty in the E3ME model indicates that, while observing the matching of supply and demand, there is no constraint that demand equals potential supply. It is thus possible to have unused resources in the market, such as unemployed workers, unused financial capital and equipment, which can be brought in for production if demand requires. E3ME describes a treatment of endogenous money which has been recognized as a major limitation in CGE models and other theoretical modelling approaches (Pollitt and Mercure, 2018). The possibility of the existence of spare resources can sometimes yield positive economic benefits of technology change policies (Mercure et al 2018).

\subsection{Data}

The tariff data used in this study are based on the HS classification. Under the HS classification, each product traded is assigned a six-digit code that represents $98 \%$ of international trade. The tariff data used for the simulations are from MAcMap from 2013 to 2017 with HS2012.

To compare the different EG classification impacts on the economy and environment, the "Core list" and "WTO list" are used in this study. The Core list includes 26 EG and the WTO lists include 536 EG. The differences between these two lists are shown in Tables A1 and A2 of the Supplementary Information. 
In addition, the current carbon taxes are based on World Bank data (World Bank 2018); each country levies or will levy different carbon taxes as shown in Table A3 of the Supplementary Information.

\subsection{Scenarios}

To understand comprehensively the impacts of trade liberalization of EG, scenarios with different EG lists, with or without end-use control and with combinations of environmental policies were set. As the EG might have multiple end-uses for both environmental and nonenvironmental purposes, the end-use control, in this study, indicates the costs of the $\mathrm{EG}\left(T C_{e}\right)$ used for non-environmental electricity production, such as coal power, is unchanged under the trade liberation tariffs policy for EG. The detail scenarios are as follows:

Baseline: the baseline simulation without the EGA and carbon tax policy from 2015 to 2030.

EG_Core: Core list without end-use control. Under this scenario, tariffs on power-sector related goods within the HS6 subheading defined in the Core list would be reduced to zero by all countries.

EG_WTO: WTO list without end-use control. Under this scenario, tariffs on power-sector related goods within the HS6 subheading defined in the WTO list would be reduced to zero.

EG_Core_EC: Core list with end-use control. Under this scenario, tariffs on power-sector related goods in the Core list would be reduced to zero, and the EG are only allowed to be used on renewable energy equipment.

EG_WTO_EC: WTO list end-use control. Under this scenario, tariffs on power-sector related goods in the WTO list would be reduced to zero, and the EG are only allowed to be used on renewable energy equipment.

TAX: The current carbon taxes for each region are put into the E3ME model. 
EGA+TAX: WTO list with end-use control combined with a carbon tax. This scenario combines EG_WTO_EC and TAX.

\section{Results and discussion}

\subsection{The global impacts of the trade liberalization of EG}

The trade liberalization of EG does not necessarily benefit the environment without other policies, as shown in Figure 1. The $\mathrm{CO}_{2}$ reductions are less than 11 million tonnes under all scenarios, comparing to the baseline emissions for 2030. This is because the changes in technology costs at HS6 category level are small, typically less than 1 percent. The unchanged of one of the largest cost components, installation, could limit the emissions reductions from the EGA. The different $\mathrm{EG}$ lists might result in quite different $\mathrm{CO}_{2}$ emissions changes. On the one hand, the elimination of EG tariffs would decrease the cost of environmental technologies and stimulate innovation and technology transfer. Access to lower-cost and more energy-efficient technologies could reduce $\mathrm{CO}_{2}$ emissions, as in the scenario EG_Core (Figure 1(a)). On the other hand, sometimes, the reduction of costs of environmental goods can also be used for fossil-based generation, as shown in Table A2 of the Supplementary Information. Some of the technologies share the same components; for example, gas turbines (HS: 841181) is one of the components for coal, natural gas, oil and biomass. Reducing the barriers of gas turbine trade would improve the technology of both renewable generation (biomass) and conventional energy (natural gas, coal and oil). Different from the Core list, the WTO list also includes Gas turbines, Tower and lattice masts of iron/steel, Heat exchange units, AC generators, Sodium nitrate, Motors, Fuel elements, Super-heated water boilers, Steam or vapor generation and other sectors. These components 
are also used in fossil-based technology. Thus, reducing EG tariffs could result in a $\mathrm{CO}_{2}$ emissions increase, as in the scenario EG_WTO in Figure 1(a).

The multiple end-uses have large impacts on $\mathrm{CO}_{2}$ emissions. Figure 1(a) shows that end-use control could largely improve $\mathrm{CO}_{2}$ emission mitigation, as in the EG_Core_EC and EG_WTO_EC scenarios. The WTO list covers more environmental goods, which would make more contributions to $\mathrm{CO}_{2}$ mitigation with end-use control.

In addition, the reduction of EG tariffs could benefit economic development. As shown in Figure 1(b), global GDP is increased under all scenarios. The reduction of import prices that originates from the reduction in tariffs could stimulate trade and increase the demand for EG. Different to an equilibrium model which assumes optimal capital accumulation over time and the optimal allocation of scarce economic resources given the technology at each points in time, the non-equilibrium model represents that economic development is path dependent and based on expectations of future financial resources, so that the economy is driven by demand (Mercure 2012). Once the entrepreneur decides to invest in producing capital and technology because of increasing demand, and the banks agree to offer loans, investment and savings both increase. Since investment is not constrained by savings, the bank loans increase debt and income simultaneously. Thus, the increasing demand of EG promotes economic growth. However, higher economic activity requires more energy and could lead to rebound effects on total emissions, which is the other reason for the small reduction of $\mathrm{CO}_{2}$ emissions. Comparing the different scenarios, the EGA without end-use control (EG_Core and EG_WTO) obtains greater GDP increases because of the multiple end-uses for both clean technology and non-clean technology causes a larger increase in the demand for EG. 

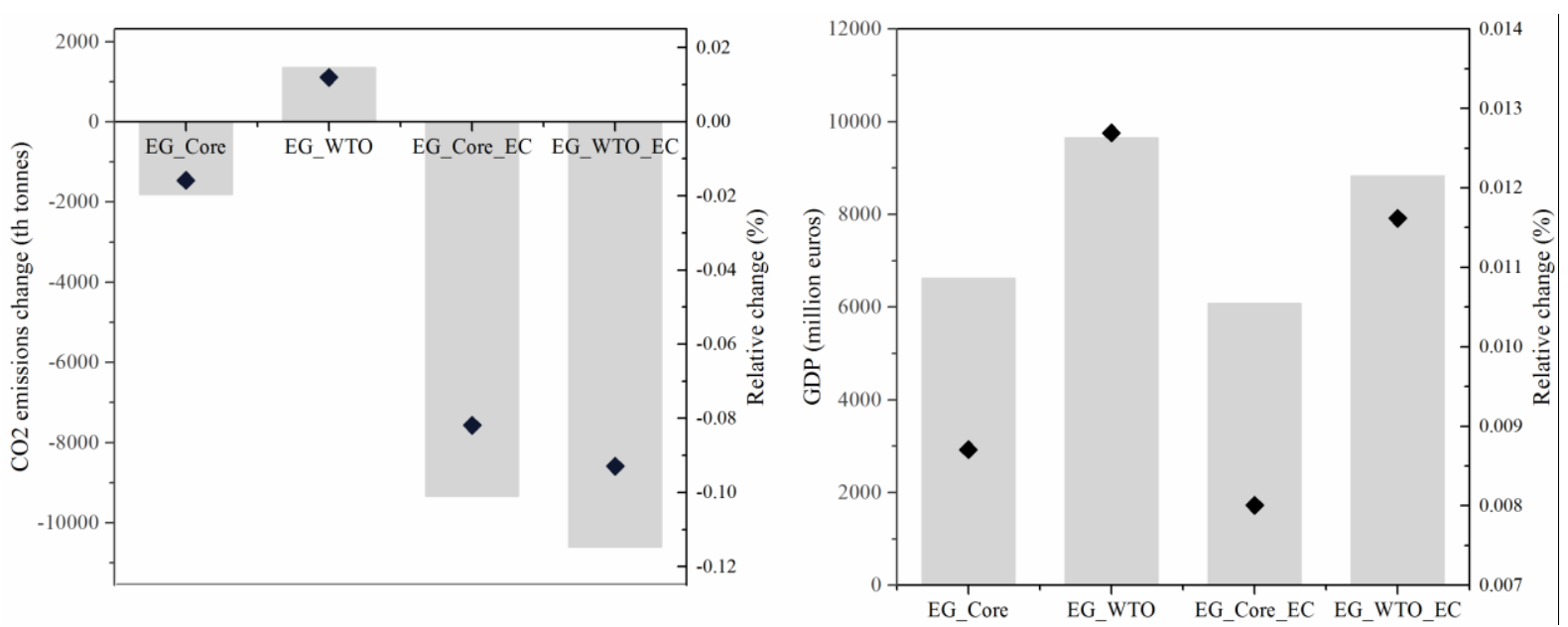

Figure 1. The trade liberalization of EG impacts on $\mathrm{CO}_{2}$ emissions and GDP under different scenarios for 2030. The gray bars show the absolute change and the black dot shows the relative change. (a) The changes of $\mathrm{CO}_{2}$ emissions without end-use control under the Core lists (EG_Core) and WTO lists (EG_WTO) and the changes with end-use control under the Core lists (EG_Core_EC) and WTO lists (EG_WTO_EC), thousand tonnes. (b) The changes of GDP under the EG_Core, EG_WTO, EG_Core_EC and EG_WTO_EC scenarios compared to baseline in 2030, million euros.

Examining electricity generation by technology, reducing EG tariffs would increase the deployment of renewable energy technology, especially for wind (including onshore and offshore) and biogas with more than a $1 \%$ increase (see Figure 2). The increase in renewables displaces fossil fuel generation with reductions in coal and integrated gasification (IGCC). Solar PV could also be reduced because the current tariffs on solar PV are small, and reducing the tariffs has little impact on the technology cost of solar PV. Solar generation is displaced by other renewable technologies as the reductions in tariffs on EG does not reduce the cost of solar and therefore it becomes less price-competitive, especially in relation to wind. Therefore, the share of solar PV could decrease. Conversely, coal has greater 
competitiveness without end-use control. The price changes are presented in Figure 3. The increase in solar PV prices is due to the lower deployment of solar PV, which means that solar does not achieve the same cost reductions from learning relative to the baseline. Thus, the EGA might have little impact on $\mathrm{CO}_{2}$ emissions.

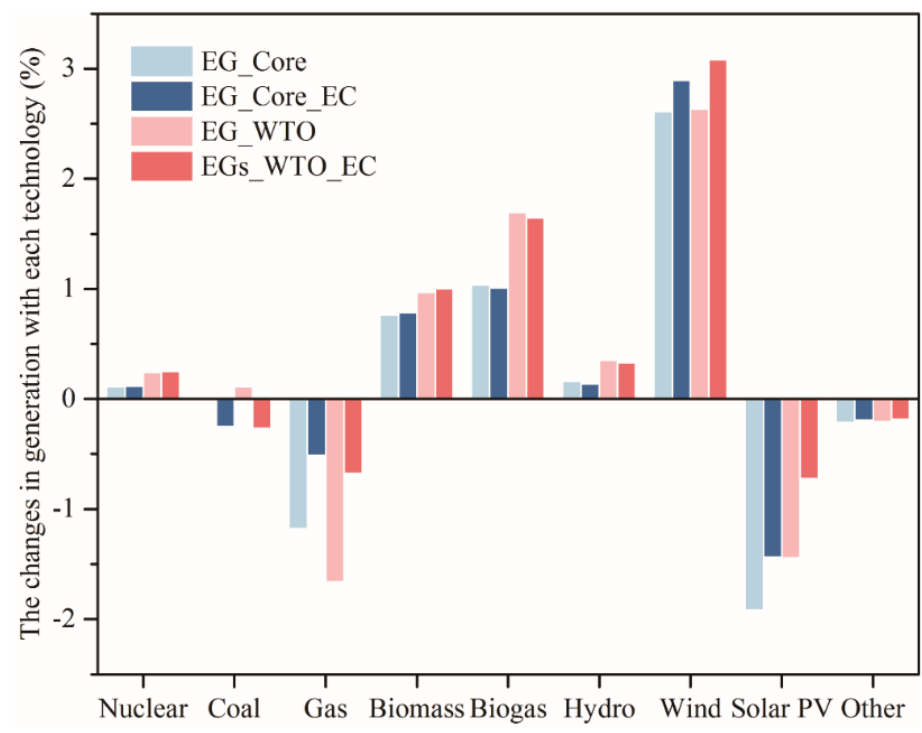

Figure 2. The percentage changes from baseline in global electricity generation by each technology under different scenarios for 2030. IGCC, integrated gasification; PV, photovoltaic.

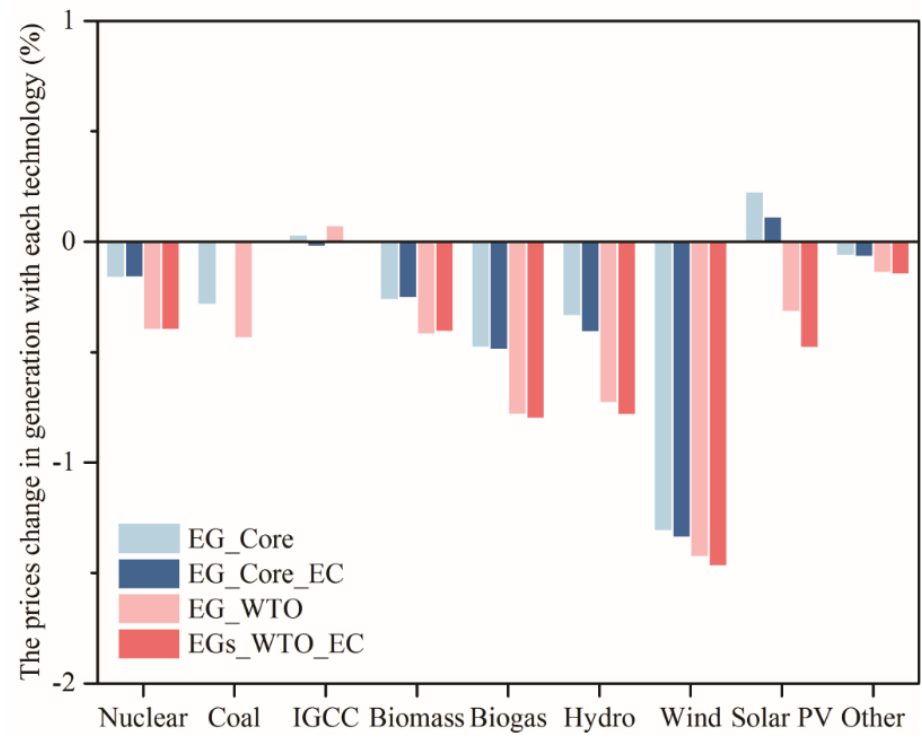


Figure 3. The percentage changes of the prices for various technologies under the EG_Core (without end-use control under the Core lists), EG_Core_EC (with end-use control under the Core lists), EG_WTO (without end-use control under the WTO lists) and EG_WTO_EC (with end-use control under the WTO lists) scenarios compared to baseline for 2030.

\subsection{Regional impacts of the trade liberalization of EG}

The impacts of the EGA are small at the macro level, but the changes differ greatly among regions. Different regions vary baseline emissions, EG tariffs and electricity generation technology components, which result in different regional $\mathrm{CO}_{2}$ emissions changes. Figure 4 shows that the EGA has a larger impact on developing countries with high EG tariffs and large baseline emissions, such as China and India. The regional average tariffs for EG are listed in Figure A1 of the Supplementary Information. Developing countries generally have larger EG tariffs than developed countries, and thereby liberating the trade tariffs would result in larger reductions of electricity technology costs (as shown in Figure A2 of the Supplementary Information). China has the largest response, with 2614 thousand tonnes, 6398 thousand tonnes, 1216 thousand tonnes and 6943 thousand tonnes reductions, respectively, for the EG_Core, EG_Core_EC, EG_WTO and EG_WTO_EC scenarios compared to the baseline emissions for 2030. In contrast, Argentina has the highest average EG tariffs, but the $\mathrm{CO}_{2}$ emissions could even increase without end-use control. This is because under EG trade liberalization, the reductions of fossil-based technology costs are close to those of renewable energy technologies, and the reduction of coal costs have small differences with wind energy (as shown in Figure A2 of the Supplementary Information). Thus, fossil fuel generation could displace renewable energy generation (as shown in Figure A3) and lead to an increase in emissions. Similarly, the increase of $\mathrm{CO}_{2}$ emissions in Russia is caused by the increase of coal demand for electricity generation, and Saudi Arabia suffers more $\mathrm{CO}_{2}$ emissions due to increased oil and coal demand. The detailed regional changes of 
electricity generation by technology under the EG_Core scenario are shown in Figure A3 of the Supplementary Information. The developed countries with small EG tariffs have relative lower reductions of $\mathrm{CO}_{2}$ emissions by the EGA. In particular, the $\mathrm{CO}_{2}$ emissions from the United States and Australia could increase under the scenarios without end-use control (EG_Core and EG_WTO). This is because a small tariff reduction has little impact on the use of renewable energy but might reduce the substitution of fossil fuels to renewable generation, thereby increasing emissions. The regional relative changes of $\mathrm{CO}_{2}$, as shown in Figure $\mathrm{A} 4$ of the Supplementary Information, also indicate that larger emissions reductions would occur in countries with higher EG tariffs and countries whose EG are more focused on renewable energy technology improvement.

As outlined previously, reducing the EG tariffs with end-use control (Figure 4 (b) and (d)) could benefit $\mathrm{CO}_{2}$ mitigation almost in every country. Thus, the regional EG components and tariffs decide their emissions reductions under the EGA. The end-use control is significant to countries where EG have large multiple end-uses for fossil-based technologies.

Moreover, the EGA has different economic impacts across regions, as shown in Figure 5. The countries with larger technology costs reductions (as shown in Table A4-A5 of the Supplementary Information) could result in higher economic benefits, such as Brazil, Argentina, Australia, Korea, India, Russia, China and Indonesia whose GDP increase under all scenarios. In the non-equilibrium E3ME model, investment is unrestricted by savings and determined by the willingness of firms to invest and the willingness of banks to lend. Thus higher demand incentivizes firms to re-invest in R\&D and to expand their capital (Mercure et al 2014). Large reductions of power generation technology costs could increase the demand for lower-cost technology, stimulate investment and benefit economic activity. Figure A5 (in Supplementary Information) presents the components of regional GDP changes under the EG_Core scenario which shows that the increases of GDP in Brazil, Australia, India, Russia 
and China mostly depend on increasing investment. Especially, in Argentina, Korea and Indonesia, who rarely produce EG, the increased output mostly comes from employment for installing these products, and increasing incomes stimulates the household expenditure.

Combining the effects on emissions and the economy under the EGA, the developing countries with high EG tariffs and large basic emissions would have larger benefits overall. In detail, trade liberalization could increase flows of technology in developing countries, which will reduce $\mathrm{CO}_{2}$ emissions. The reduction of costs caused by tariff removal could stimulate investment in EG and benefit economic development for developing countries.

(a) EG_Core

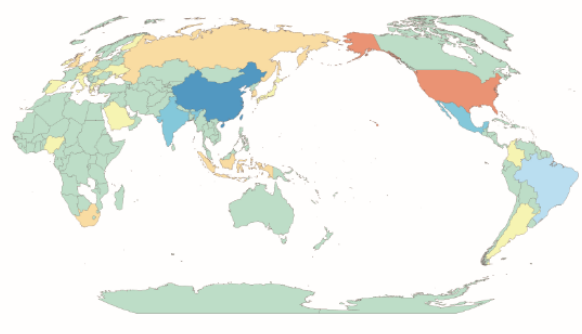

(c) EG_WTO

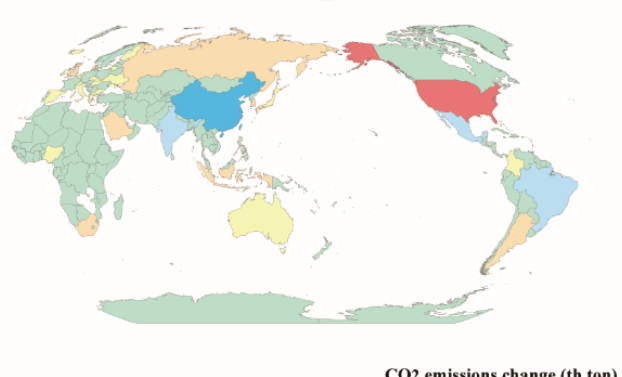

$\mathrm{CO} 2$ emissions change (th ton) (b) EG_Core_EC

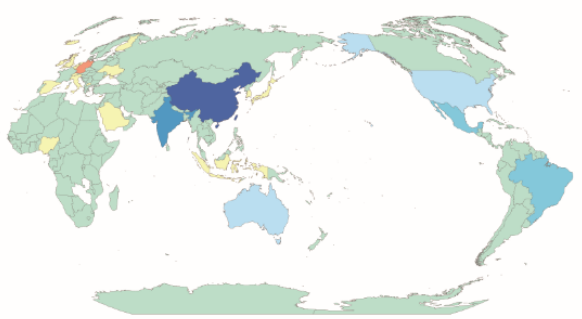

(d) EG_WTO_EC

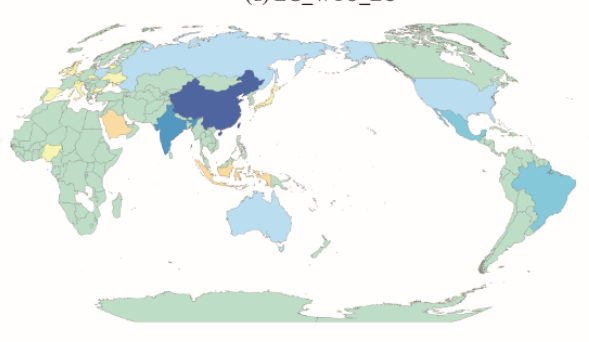

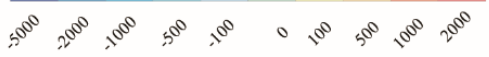

Figure 4. The changes of regional $\mathrm{CO}_{2}$ emissions under different scenarios from baseline for 2030, thousand tonnes. (a) EGA based on the Core list without end-use control, (b) EGA based on the Core list with end-use control, (c) EGA based on the WTO list without end-use control and (d) EGA based on the WTO -5000list with end-use control. 

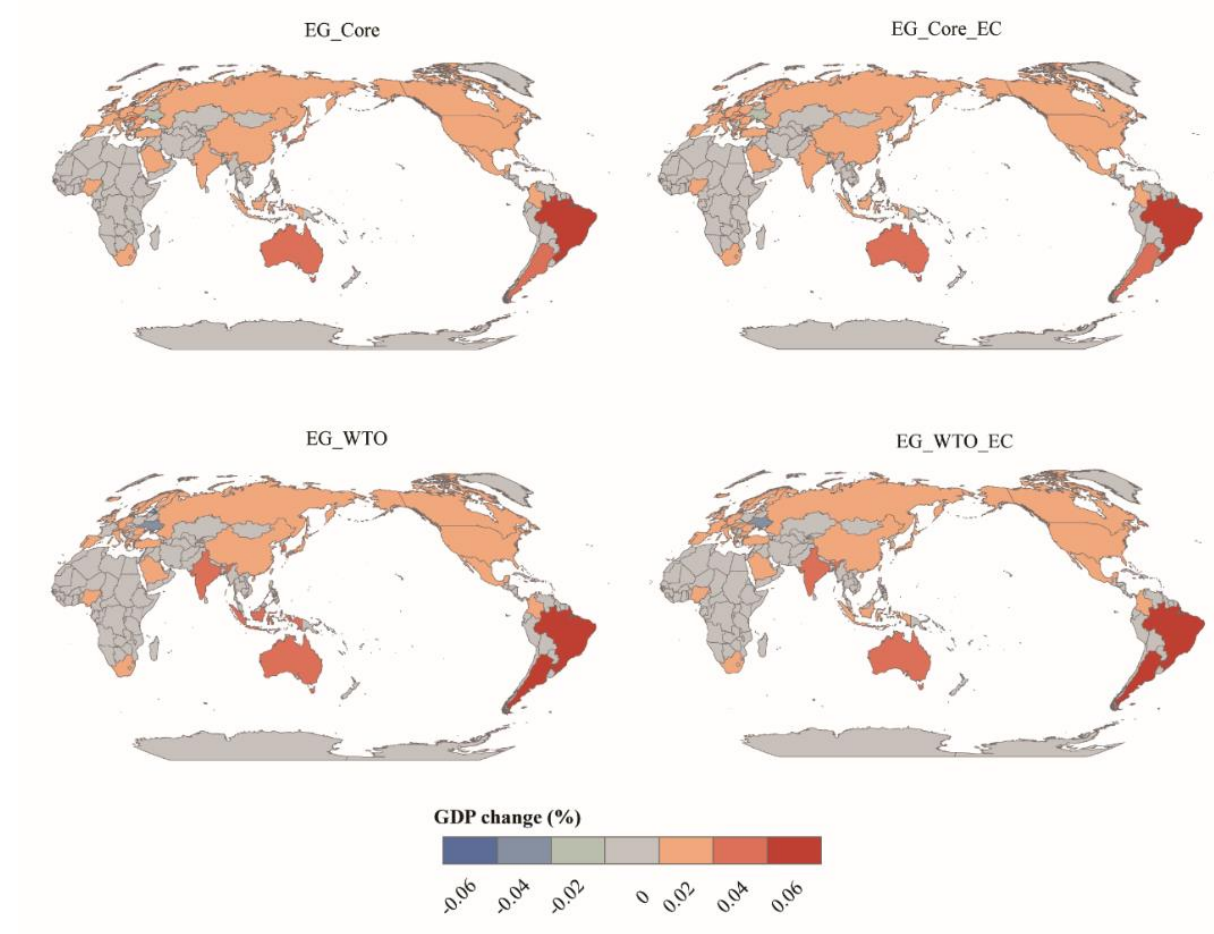

EG_WTO_EC

Figure 5. Relative change of regional GDP under the Core list without and with end-use control (EG_Core, EG_Core_EC), WTO list without and with end-use control (EG_WTO, EG_WTO_EC) scenarios compared to baseline for 2030, \%.

\subsection{The combination of the EGA and carbon tax policy}

The EGA with end-use control could improve $\mathrm{CO}_{2}$ emissions mitigation, but the impacts are quite small. Even under the most stringent scenario, $\mathrm{CO}_{2}$ emissions reduction is just 10.6 million tonnes $(0.09 \%)$, because the technology cost reductions are so small, typically less than 7\% (as shown in Table A4 of the Supplementary Information), and the installation costs of technology remain unchanged. As a result, there is slower deployment in renewable technology, and in the case of the solar PV, it may even decrease. Moreover, higher energy demand due to higher economic activity might offset the cleaner generation mix and lead to more emissions. Therefore, other environmental policies should be considered simultaneously. The carbon tax can be a cost-effective tool for reducing $\mathrm{CO}_{2}$ emissions 
(Endre and Michael 2018). Here, we combine the EGA (the most stringent scenario, EG_WTO_EC) with a carbon tax to analyse the interaction between these two policies.

Figure 6 shows that merging EGA into a global carbon tax system would significantly enhance the effects of the carbon tax on $\mathrm{CO}_{2}$ reduction (by 33\%), and simultaneously lower the GDP loss due to the carbon tax by $75 \%$. The EGA could reduce the prices of renewable energy through the subsidy of energy technology costs, and the carbon tax could increase the prices of fossil-based energy; therefore, these two policies could result in renewable energy becoming more cost competitive by substituting for fossil fuels and decreasing $\mathrm{CO}_{2}$ emissions further. For economic development, the EGA could offset the negative economic impacts from the carbon tax. As discussed above, the EGA could increase GDP. In contrast, the carbon tax could increase the prices of emission-intensitive sectors and further increase average market prices through intersectoral activities. Rising prices could reduce product demand and decrease the GDP. Accordingly, the increases in GDP from the EGA could offset the decreases in GDP from the carbon tax. Thus, the combination of these two policies could simultaneously improve $\mathrm{CO}_{2}$ emissions mitigation and decrease the economic costs of environmental protection. The same conclusions can also be found for 2020 with a global uniform carbon tax of 50€/t $\mathrm{CO}_{2}$ (Knobloch, et al., 2018; Guivarch \& Rogelj, 2017), as shown in Figure A6 of the Supplementary Information. The $\mathrm{CO}_{2}$ emissions changes are dominated by carbon tax policy. The combination of the EGA and the carbon tax could increase the $\mathrm{CO}_{2}$ emissions mitigation and reduce the costs of this mitigation. 
(a)

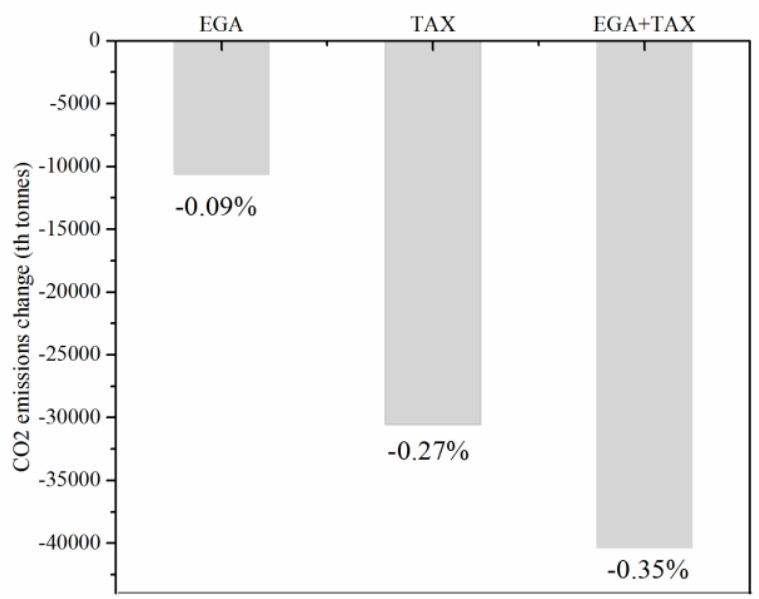

(b)

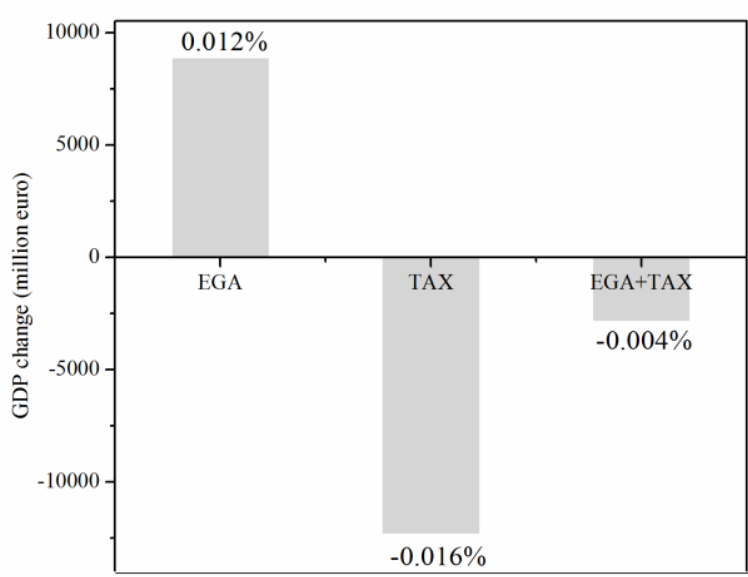

Figure 6. The EGA and carbon tax impacts on $\mathrm{CO}_{2}$ emissions and GDP. (a) $\mathrm{CO}_{2}$ emissions changes (thousand tonnes) under the EGA, TAX and EGA+TAX scenarios compared to baseline for 2030. (b) GDP changes (million euro) under the EGA, TAX and EGA+TAX scenarios compared to baseline for 2030 .

Examining power generation by technology, the large improvement in renewable energy under a carbon tax comes from an increase in solar PV and reduction in coal, which would result in a cleaner energy structure for the electricity sector (see Figure 7). There would be large increases in renewable generation such as offshore wind, onshore wind, biogas, biogas with CCS and wave, and solar PV also increases under the EGA+TAX scenario. Fossil fuels (oil, coal and CCGT) decrease due to the carbon tax. 


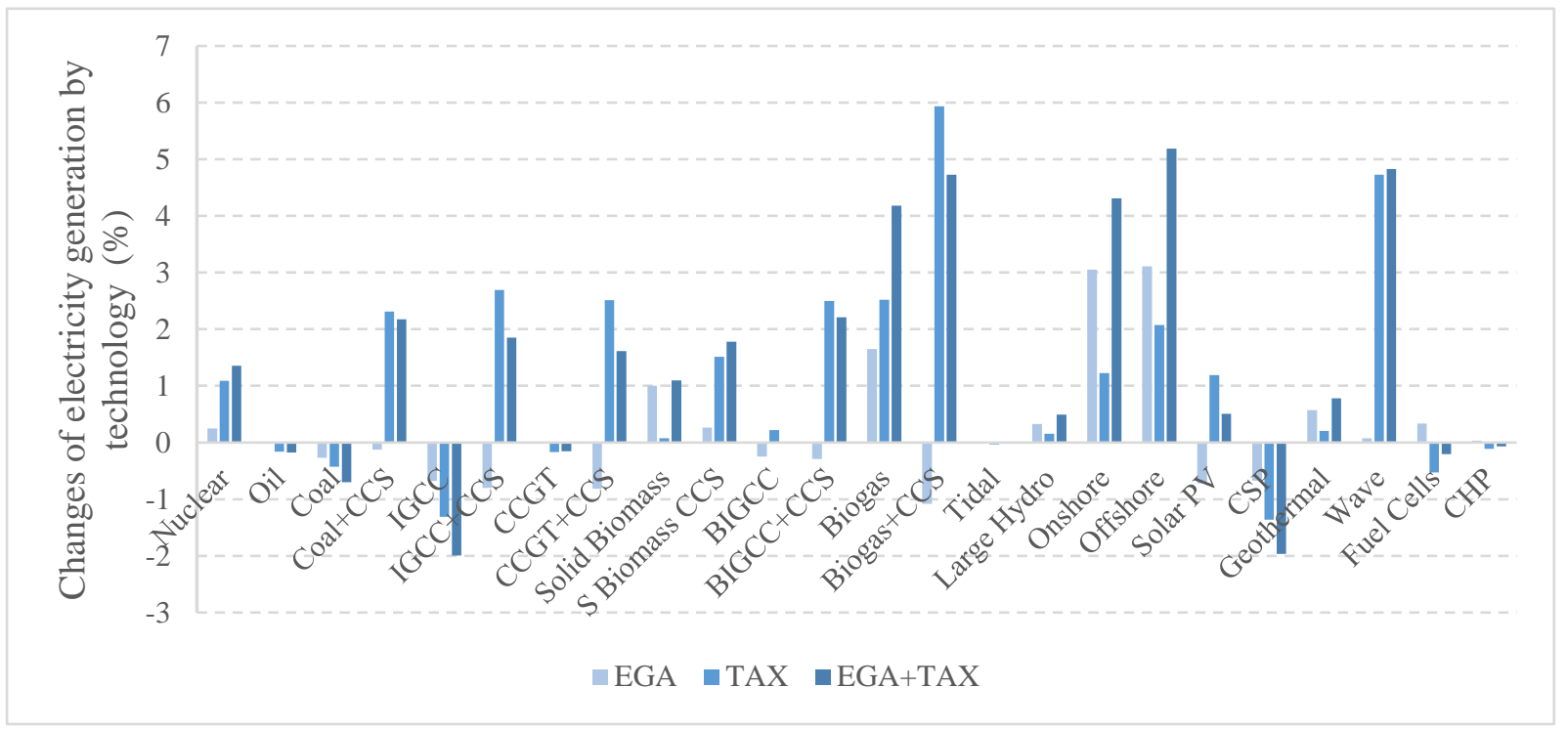

Figure 7. The percentage changes in global electricity generation by each technology under the policies of the liberalization tariff of environmental goods (EGA), a carbon tax (TAX) and the combination of them (EGA+TAX) compared to baseline for 2030. CCS, carbon capture and storage; IGCC, integrated gasification; CCGT, combined cycle gas turbine; BIGC, biomass IGCC; PV, photovoltaic; CSP, concentrated solar power; CHP, combined heat and power.

\section{Conclusion and Policy Implications}

The trade liberalization of EG does not necessarily benefit the environment without other policies, since the multiple end-use of EG might result in environmental damage. In this situation, the smaller EG list, which is more focused on EG used in clean energy technologies, could be better than larger lists, because larger lists could include more products used in fossil fuel energy production. End-use control is important for both global and regional EGA policy. Therefore, end-use control measures should be considered for the EGA. For example, we could collect the EG tariffs first and then return revenues back to the 
industry whose products are used in renewable energy production. Concerning the economy, the reduction of import prices that originates from the tariffs cut could stimulate international trade and increase EG demand. This increasing demand promotes production and benefits economic development. For the regional effects, in general, developing countries with high EG tariffs and large basic emissions could have larger benefits to both economy and environment. These results might promote developing countries, who are reluctant to make such agreements in order to safeguard their own enterprises (ICTSD 2008), to join the EGA. Liberalizing EG tariffs could provide rapid access to key technologies to developing countries and help them build up their own productive and technological capacities in this area. In addition, end-use control is crucial for countries whose fossil-based technology cost changes are close to those of renewable energy technologies under the EGA, like Argentina.

Although the EGA alone can contribute to only a small part of $\mathrm{CO}_{2}$ emission reductions, merging EGA into a global carbon tax system would significantly enhance the effects of a carbon tax, by $33 \%$, and simultaneously lower the GDP loss due to the carbon tax by $75 \%$. Thus, the combination of the EGA with other environmental policies could improve $\mathrm{CO}_{2}$ emissions and offset the negative impacts of the other policies. In other words, countries pursuing green environmental policy will benefit from the EGA with more potential for the diffusion of renewable technologies and lower costs. The underlying connection among the EG list, EG trade policy and other environmental policies should be considered in the setting of international trade agreements that target EG.

This study attempts to close the gap in integrated analysis for EG trade through the power sector. However, there are still limitations on the basic data and assumptions in the model. For example, the tariff data based on HS codes do not classify goods based on their end-use, and there is only a six-digit level for global use. For example, the HS code of a water heater is 841919 , but a solar water heater might be defined at an eight-digit level, such as 84191910 
in China. Therefore, the elimination of EG tariffs with a six-digit level might overestimate the EG effects. To address this issue, the APEC economies pointed out "ex-heading" to describe a specific product with duty-free treatment. These "ex-heading" EG products are just parts of the six-digit HS definition, shown in Table A6 of the Supplementary Information. To testify the sensitivity of the WTO list with six-digit HS codes, we remove all the "ex-heading" products out of the WTO list and strictly focus on the HS codes for which all the products are EG. Comparison of the outputs before and after removal are shown in Figure A7 of the Supplementary Information. The results show that the elimination of EG tariffs at six-digit level might lead to $5 \%(0-10 \%)$ overestimation of the EG effects.

In addition, when calculating the energy technology costs, we assume that domestic producers will reduce prices consistently with import prices, which has a possibility to overestimate EG effects. Lower import prices caused by trade liberalization would increase import penetration which might greatly impact on domestic prices (Saggay et al 2007). Thus, we follow the study of European Commission (2016), and assume that the domestic producers will reduce prices in line with import prices (the highest impacts from EGA policy). We also provide the results of the minimum impact on domestic prices from the EGA policy, with the assumption that domestic prices are unchanged (though, in reality, this extreme case is unlikely to happen). We find there are about $25 \%(0-40 \%)$ differences in EG effects between these two assumptions (see Figure A8 in the Supplementary Information). While uncertainty remains, the global and regional changes are consistent under all scenarios. In the future, the results could be further improved if more information, especially on import penetration and the changes in domestic prices affected by the trade liberalization, will be available for every country. 


\section{Acknowledgements}

This work was supported by funding from the National Natural Science Foundation of China under award nos. 41671491 and 41821005, the Newton Advanced Fellowship (NAFR2180104) and the National Key Research and Development Program of China 2016 YFC0206202.

\section{References}

Arun, J. and K. M. Anders (2016). Policy landscape of trade in environmental goods and services. International Green Trade Conference. Beijing, China. 166.

Barker, T., S. Junankar, et al. (2007). "Carbon leakage from unilateral Environmental Tax Reforms in Europe, 1995-2005." Energy Policy 35(12): 6281-6292.

Bucher, H., J. Drake-Brockman, et al. (2014). "Trade in Environmental Goods and Services: Opportunities and Challenges."

Cambridge Econometrics (2014). E3ME Technical Manual, Version 6.0.

de Alwis, J. M. D. D. J. (2014) Environmental Consequence of Trade Openness for Environmental Goods. 16, 79-98

Dijkstra, B. R. and A. J. Mathew (2016). "Liberalizing trade in environmental goods and services." Environmental Economics \& Policy Studies 18(4): 1-28.

Endre, T. and M. Michael (2018). "Carbon pricing and deep decarbonisation." Energy Policy: 185-189.

European Commission (2015). Trade Sustainability Impact Assessment on the Environmental Goods Agreement. 
European Commission (2016). Trade Sustainability Impact Assessment on the Environmental Goods Agreement.

Guivarch, C., Rogelj, J., et al., 2017. Carbon price variations in $2^{\circ} \mathrm{C}$ scenarios explored. Carbon Pricing Leadership Coalition.

Hammeren, L. (2014). "Sustainable Development and Liberalization of Trade in Environmental Goods: An analysis of the APEC and WTO initiatives." Department of Industrial Economics \& Technology Management.

ICTSD (2008). Liberalization of Trade in Environmental Goods for Climate Change Mitigation: The Sustainable Developing Context, International Centre for Trade and Sustainable Development.

Knobloch, F., Pollitt, H., Chewpreecha, U., Daioglou, V., Mercure, J.-F., et al., 2019. Simulating the deep decarbonisation of residential heating for limiting global warming to 1.5 ${ }^{\circ} \mathrm{C}$. Energy Efficiency 12 (2), 521-550.

Krey, V., G. Luderer, et al. (2014). "Getting from here to there - energy technology transformation pathways in the EMF27 scenarios." Climatic Change 123(3-4): 369-382.

LaFleur, M. (2011). "LaFleur, Marcelo. The liberalization of environmental goods and services: overview and implications for Latin America and the Caribbean[J]. 2011." ECLAC.

Lee, S., U. Chewpreecha, et al. (2017). "An economic assessment of carbon tax reform to meet Japan's NDC target under different nuclear assumptions using the E3ME model." Environmental Economics \& Policy Studies 20(2): 1-19.

Melo, J. D. and M. Vijil (2014). "Barriers to Trade in Environmental Goods and Environmental Services: How Important are They? How Much Progress at Reducing Them?" Cepr Discussion Papers. 
Mercure, J.-F., F. Knobloch, et al. (2019). "Modelling innovation and the macroeconomics of low-carbon transitions: theory, perspectives and practical use." Climate Policy 19(8): 10191037.

Mercure, J. F. (2012). "FTT:Power : A global model of the power sector with induced technological change and natural resource depletion." Energy Policy 48(3): 799-811.

Mercure, J. F., H. Pollitt, et al. (2014). "The dynamics of technology diffusion and the impacts of climate policy instruments in the decarbonisation of the global electricity sector." Energy Policy 73(13): 686-700.

Mercure, J. F., H. Pollitt, et al. (2018). "Environmental impact assessment for climate change policy with the simulation-based integrated assessment model E3ME-FTT-GENIE." Energy Strategy Reviews 20: 195-208.

Mercure, J. F., H. Pollitt, et al. (2018). "Macroeconomic impact of stranded fossil fuel assets." Nature Climate Change 8(7).

Mitchell, C. (2016). "Momentum is increasing towards a flexible electricity system based on renewables." Nature Energy 1(2): 15030.

Nimubona, A.-D. (2010). "Pollution Policy and Liberalization of Trade in Environmental Goods." Working Papers 1004.

Pollitt, H., S. Lee, et al. (2015). "The macroeconomic impacts of environmental tax reform: A comparison of model results." Taylor and Francis Inc.: 140-150.

Pollitt, H., Mercure, J.-F., et al., 2018. The role of money and the financial sector in energyeconomy models used for assessing climate and energy policy. Climate Policy 18 (2), 184197. 
Pollitt, H., S. J. Park, et al. (2014). "An economic and environmental assessment of future electricity generation mixes in Japan - an assessment using the E3MG macro-econometric model." Energy Policy 67(4): 243-254.

Randalls, S. (2010). "History of the $2^{\circ} \mathrm{C}$ climate target." Wiley Interdisciplinary Reviews Climate Change 1(4): 598-605.

Razzaque, J. and B. Chaytor (2004). "Liberalising Trade in Environmental Goods and Services: In Search of 'Win-Win-Win' Outcomes." Social Science Electronic Publishing,. Saggay, A., A. Heshmati, et al. (2007). "Effects of trade liberalization on domestic prices: Some evidence from Tunisian manufacturing." International Review of Economics 54(1): 148-175.

Steenblik , R. (2005). Environmental goods: a comparision of the APEC and OECD list. Joint Working Party on Trade and Environment OECD Publications.

Wan, R., M. Nakada, et al. (2018). "Trade liberalization in environmental goods." Resource and Energy Economics 51: 44-66.

Williams, J. H., D. B. Andrew, et al. (2012). "The technology path to deep greenhouse gas emissions cuts by 2050: the pivotal role of electricity." Science 335(6064): 53-59.

World Bank (2018). "State and Trends of Carbon Pricing 2018." World Bank Other Operational Studies.

WTO Environmental Goods Agreement.

Zugravu-Soilita, N. (2018). "The impact of trade in environmental goods on pollution: what are we learning from the transition economies' experience?" Environmental Economics \& Policy Studies 20(6): 1-43. 
